\title{
The manual skills and cognition that lie behind hominid tool use
}

\author{
Richard Byrne \\ University of St Andrews, Scotland
}

\author{
[In A E Russon and D R Begun (Eds.) Evolutionary origins of great ape intelligence. Cambridge \\ University Press, in press.]
}

Tool use is an important aspect of being human that has assumed a central place in accounts of the evolutionary origins of human intelligence. This has inevitably focused a spotlight on any signs of tool use or manufacture in great apes and other non-human animals, to the relative neglect of skills that do not involve tools. The aim of this chapter is to explore whether this emphasis is appropriate. Could it be that we may learn as much about the origin of human intelligence from skilled manual behaviour in general? Suppose we take this broader view, accepting evidence from all manifestations of manual skill, what can we learn of the mental capacities of the great apes and ourselves? My own ultimate purpose is to use comparative evidence from living species to reconstruct the evolutionary history of the many cognitive traits that came together to make human psychology. The cognition of great apes is the obvious starting point, to trace the more primitive (i.e. ancient) cognitive aptitudes that are still important to us today. In this chapter, I focus on great ape cognition as it is expressed in manual skills, based on cognitive aspects of tool use and manufacture considered significant in the human evolutionary lineage.

\section{Why is tool use important in the study of human evolution?}

Consider first what aspects of tool use have recommended it as "special" to physical anthropologists and archaeologists. Most obviously, tools are convenient things for investigators. As physical objects, they can be collected, measured, and compared with ease. Often durable, they can be investigated long after the tool user or maker is dead. For archaeologists, this characteristic alone adds enormous value to tools in the study of human origins. Convenience alone would be little recommendation if tool skills were trivial. But of course, quite the reverse is believed to be the case.

The significance of tools is what they imply about the cognitive abilities of their users. From examining the products of tool making and using, researchers hope to discern the thinking that governed these activities: everyday physics, means-end analysis, coordination of dextrous 
manipulations towards a predefined goal, recognizing and coping with local difficulties in a complex process, and so on. I contend that these cognitive abilities are equally required by many tasks that do not involve tool use, especially complex manual skills, and that neglect of the study of manual skills has been an impediment to understanding great apes' technological abilities, and therefore to understanding the evolutionary origins of human technological ability (Byrne 1996, 1999; and see Yamakoshi, this volume, for a related view).

Moreover, little help in understanding the origins of complex manual skills has been available from psychology. The mechanisms controlling reaching and grasping and their development have been carefully analysed (Connolly 1998; Fitts \& Posner, 1967), but until recently little attention has been paid to what is done with an object once grasped (Bril, Roux, \& Dietrich, 2000; Roux, 2000). This chapter, then, also constitutes something of a plea for broader-based research on the psychology of skill acquisition, and the relationship between complex manual tasks and mental abilities.

\section{What is special about human tool use?}

Identification of qualitative differences between human and non-human tool making may enable us to identify which facets of cognition and which particular aspects of technical skills were likely to have been crucial in human evolution. Some clear differences have been suggested. All known human populations fabricate composite tools out of many component parts (Gosselain, 2000; Reynolds, 1982): nets, hafted spears, and even boats. Also, human tools are often used to make or assist other tools, in a range of ways, from slings and throwing sticks, to carving wood with adze and knife or smelting metal. And human tool materials range from wood and stone to hair, bone, horn, plant seeds, and metal, according to the task in hand. Tools of non-humans are poor things in comparison (unless bee and wasp nests, and the bowers and nests of birds, are treated as tools, in which case the contest is a closer one: but these feats are species-typical and presumably innately coded).

However, those highly distinctive characteristics of human tool making-composite tools, tool-use to make tools, the rich array of raw material—may be relatively new even in human evolution (Mellars \& Stringer, 1989). In hominin deposits that date from before the arrival of anatomically modern humans, archaeologists are hard pressed to find uncontroversial evidence of tools going beyond single items, made by removing parts rather than combining items, and only of stone or sometimes wood. The animals that made these simpler tools were anatomically much closer to modern humans than they were to living great apes. We may fairly ask, then, whether there exist critical aspects of human tool making, and the cognitive abilities 
that they imply, that predate anatomically modern humans. If so, other less ostentatious capacities may represent derived cognitive features of the human lineage, "special" nonetheless because they are shared by some of our extinct relatives but not by any other living animal ${ }^{1}$. Alternatively, the tools of the earliest members of the human lineage and their relatives may have tapped only primitive cognitive capacities shared with living non-human primates. It is of course possible that all these accounts are true for different aspects of tool-related cognition: some uniquely human, some unique to the human line, some shared with living great apes, and some shared with a much wider range of species. Modern human competence with tools may have a long evolutionary history.

To find out, the most crucial species to examine are our closest living relatives, the great apes. All great apes sometimes use tools (McGrew, 1989). The lesser apes do not use tools and little is known of their manual skills, so they will not be considered further; "apes", hereafter, will refer to great apes. Are there unique features of the tool skills of the great ape clade (including humans)? To find out, it is necessary first to establish a baseline, asking: what tools do non-ape animal species use?

\section{Tool using in animals other than apes}

Although most species use none, tool use is quite widely distributed across animal taxa (Beck, 1980). In many cases, the available evidence constitutes only a single reported instance of a particular individual making a particular tool, and provides little detail on method (e.g. Chevalier-Skolnikoff \& Liska, 1993). This picture is as true of monkeys as it is of most other animals. Some species of animal, but not monkeys, do use tools habitually, in consistent ways In these cases, individuals are often found to use one sort of tool for one purpose, but members of closely related species show no tool use or any other exceptional behaviour. Famous examples are the woodpecker finches of the Galapagos (where no true woodpeckers exist), which use cactus spines as probes; Egyptian vultures, which use stones to break ostrich eggs; and Californian sea otters, which use stones to break the shells of molluscs. Other species of Darwin's finch, and other species of otter, do not use tools.

Since habitual tool use of non-apes is generally limited to one species in a large clade, and the tool use functions in a highly specific way, the distinction might be that ape tool use is learnt from experience, while tool use in other animals is innate, coded on the species' genes. Unfortunately for this tidy partitioning, some non-apes do learn their tool using habits. Only certain populations of Egyptian vultures have discovered how to use stones to break into ostrich eggs; others cannot exploit this valuable resource; and learning is likely involved (Goodall and 
van Lawick, 1966). The most telling signs of learning tool use come from the sea otter where and traditional transmission is involved. Alaskan sea otters do not use tools but Californian otters (the same species) show either of two tool techniques, with different sized stones, to break either abalones and crabs. Abalones and crabs occur in the range of all otters, but individuals specialize on one or the other, and daughters acquire the same tool technique as their mothers (Riedman, Staedier, Estes, \& Hrabrich, 1989).

If incidental/habitual and learned/innate distinctions do not hold up, will some other split serve to characterise the uniqueness of ape tool use? Otters, vultures and finches may use tools, but do not manufacture them (unless detaching cactus spines is accepted as manufacture). Orangutans (van Schaik, 1994) and chimpanzees (Goodall, 1964) do sometimes manufacture tools. Until recently, the possibility that the crucial distinction is that manufacture of tools is unique to apes worked well. Now, however, some local populations of New Caledonia crows Corvus moneduloides have been found to manufacture tools, modifying stems and leaves to create hooks and barbs for extracting insects from crevices (Hunt, 1996, 2000).

\section{A chimpanzee's view of the archaeological record of tool use}

Although no such simple dichotomy marks out ape tool use from that of all other animals, for an evolutionist the behaviour of apes nevertheless has a special relevance to the understanding of human origins. When humans and apes are alike in some trait, not shared by other anthropoid primates, the trait is likely to exist by virtue of common descent-whereas any similarity with crows and otters doubtless results from convergent evolution. . What ape tool use amounts to and whether it differs in any crucial way from that of the early representatives of the human lineage, then, potentially informs us about the evolutionary history of distinctively human mental abilities.

One living ape, the chimpanzee, is famous for its range of habitual tool use and tool manufacture in the wild. Found stones are employed to hammer open nuts on wood or stone anvils, sticks are used to pick up ants, stems and vines to "fish" for termites in their mounds or ants within arboreal nest-holes, leaves as rain shelters or sponges or cleaning tissues, etc. (Boesch \& Boesch, 1990; Goodall, 1986; McGrew, 1992; Nishida, 1986; Sugiyama, 1994; Sugiyama \& Koman, 1979; Yamakoshi, this volume). Their methods of making tools from plants alone include detaching plant material, cutting it to length, removing leaves or bark, and sharpening the end-or all of these methods, for a single tool. Orangutans also make tools of plant material (Fox, Sitompul, \& Van Schaik, 1999), for probing and scraping. 
These discoveries make it impossible to disregard the potential importance of plant material and found objects in ancestral humans' tool use, although archaeologists will seldom detect them. Archaeology nonetheless reveals one characteristic not shown by any living great ape under natural conditions, percussion flaking of stone. One line of argument would have us stop there. Humans make stone tools, (some of) their extinct ancestors and relatives did too, but apes (and other animals) don't.

However, the significance of stone tool use and manufacture is not simply the kind of physical material is used and modified, but what we can glean about the cognitive capacities of the tool user. In exploring what stone flaking tells us about the mind of the tool-maker, we are very dependent on the quality of the evidence and the level of analysis it can sustain. At one level, percussion flaking is simply the modification of a found object by detachment of parts. As such, it falls in the same category as a chimpanzee stripping off the leaves and sharpening the tip of a stem. At another level, the particular method of stone modification may imply greater cognitive abilities in our extinct ancestors, but in the case of stone tools traditionally described as Oldowan, this implication has been disputed (Wynn \& McGrew, 1989).

Without necessarily accepting the conclusion, the process of point-by-point comparison in this argument is informative (see Joulian, 1996, for detailed analysis of chimpanzee behaviour from an archaeological perspective). Percussion flaking shows the ability to aim blows with care and precision. So, however, does a chimpanzee's hammering open a Panda nut (Boesch \& Boesch, 1990). Young chimpanzees' blows are usually ineffective, only knocking the nut away, and it takes years for a chimpanzee to become proficient, so comparable levels of precision may arguably be required. Oldowan tools are clearly made to a simple design concept: small enough to hold and with a sharp edge (Roche, 1989; Toth, 1985b). But so are a chimpanzee's termiting probes: sufficient flexibility, length, and smoothness to penetrate deep into a termite mound (Goodall, 1964). Because the probes are sometimes made in advance of reaching the mound, the chimpanzee must possess some concept of an adequate tool (Goodall, 1986). Percussion flaking also normally implies bimanual handling. But Oldowan stones may sometimes have been flaked by throwing them against a hard surface, a techinique that one bonobo discovered and used successfully (Toth, 1985b; Toth, Schick, Savage-Rumbaugh, Sevcik, \& Rumbaugh, 1993).

For the more advanced products of the middle and upper Paleolithic, and even some lower Paleolithic stone cultures (e.g. Acheulean), a very different picture emerges. Precision handling (Napier, 1961), bimanual role differentiation in which the two hands perform in different but complementary tasks (Elliott \& Connolly, 1984), very precise aiming of powerful blows, and a sequential plan of flake removal are all essential to make tools characteristic of these 
cultures. Also evident within the process are hierarchical organization and exquisite guidance by an anticipatory schema of the finished product - in Acheulean hand-axes, for instance, iterative detachment of large flakes followed by corrective detachments towards a straight edge (Wynn, 1988), and in Levallois "tortiseshell flakes", elaborate preparations before the final blow (Oakley, 1949). Until recently, it was possible to argue for a relatively late origin for these distinctively human skills in tool manufacture, and to portray the earlier, Oldowan skills as apelike, differing only in the matter of the material used.

Remarkable evidence now shows that this picture is not correct, and also illustrates the fragility of deduction from the patchy archaeological record, especially concerning ascriptions of incompetence. Roche et al (1999) excavated stone material from Lokalalei, Kenya, dating from $2.34 \mathrm{Mya}$ (well before typical Oldowan dates), that allows reconstruction of the process of detachment of up to 30 flakes from a single artefact, by a "refit" of the debris. A large series of stone cores show the same principles applied to each, and knappers were clearly able to maintain the precise strike angle for successful flaking throughout these long manufacturing sequences. The tools and their debris are not associated with skeletal material, so which species made them is not known. What is clear is that these human-like capacities of tool manufacture, well beyond the cognitive capacities shown in ape tool use, are more ancient than ever suspected.

\section{Assessing the cognition of ape manual skills}

We can then use the distinctive cognitive characteristics known to be associated with tool use in Homo sapiens, whether extinct hominins or modern people who still make their own tools, as a guide to what evolutionary precursors of modern human skills might in principle be found in living apes. In the following list, I have omitted those cognitive features that seem characteristic only of anatomically modern humans: use of tools to make tools, constructing new objects out of multiple components, and using a wide range of raw material for tools. In addition, I largely omit discussion of an important archaeological feature, material transport, in which raw material is carried to a suitable working site or working takes place where material occurs and finished tools are then transported. Living apes are primarily forest animals with relatively small home ranges: they have little or no need of systematic transport of materials, so lack of it tells us little of their cognitive capacities. The aim of the following list is to concentrate on features likely to offer helpful guidance to manual skills in apes, skills that therefore predate the divergence of the human lineage.

- precision handling: e.g. tip-to-tip precision grips, rather than whole-hand power grips useful only in rough and ready manipulation (Christel, 1993; Marzke \& Wullstein, 1995). 
- accurate aiming of powerful blows: e.g. to detach a useful flake, blows must be highly accurate in placement, yet still forceful (Inizian, Reduron-Ballinger, Roche, \& Tixier, 1999).

- bimanual role differentiation: e.g. holding a stone securely while aiming a blow at it with a hammer - the two hands perform different actions but in a complimentary way, so that they work together to achieve a single purpose (Connolly, 1998; Elliott \& Connolly, 1984).

- regular and sequential plan: e.g. in percussion flaking, the order of detachments is normally crucial to the final result (Inizian, et al., 1999; Pelegrin, 2000).

- hierarchical organization with use of subroutines (Bruner, 1970; Elliott \& Connolly, 1974; Lashley, 1951; Miller, Galanter, \& Pribram, 1960): e.g. flake detachments may be grouped into several series, of variable length according to the particular properties of the stone being worked, and each series achieves a distinct purpose - the overall plan of manufacture therefore consists of several subroutines, each performed to a local criterion of completeness (Inizian, et al., 1999; Pelegrin, 2000).

- corrective guidance by anticipatory schema, i.e. actions corrected to attain a goal specified in advance (de Groot, 1965): e.g. if there is no appropriate angle for flaking, then first construct a platform; if the main flakes do not produce a straight cutting edge, then make additional small detachments until straightness is achieved (Pelegrin, 2000; Wynn, 1988).

- high individual manual laterality: e.g. in a community of tool-makers, each individual always uses the same hand for the same task (Marchant, McGrew, \& Eibl-Eibesfeldt, 1995).

- population right-handedness: e.g. for tool-making, a significant majority of individuals are similarly lateralized, such that the left hand provides support while the right applies precision actions (Marchant, et al., 1995; McManus, 1984).

With this perspective, we can now examine evidence from the living great apes. As emphasized earlier, this evidence need not be restricted to tools. In particular, manipulation of plant material may tap the same cognitive processes as tool use: both deal with operations that change the physical world, often by applying force, so both rely heavily on understanding causeeffect and organizing simple movements into complex programs (and see Yamakoshi, this volume). I therefore draw also on the gathering and processing of plant foods by great apes, as manifestations of manual skill.

Two provisos should be mentioned, to avoid misunderstanding: both concern the meaning of skill. Firstly, to ethnographers and social anthropologists, skilled manual activity is seen as necessarily "situated": not the actions of single, clever individuals but within a social network of knowledge and support. Almost all the great ape skills described here are sometimes performed in social circumstances, and social transmission of this expertise is considered crucial. 
However, to date, most study has focused on individual apes rather than a social nexus. The aim of this chapter is therefore a more modest one, to characterize the cognitive processes of great apes relating to their ability to master complex manual skills. Secondly, in some branches of psychology (e.g. sport psychology), "skill" refers to the degree of perfection of muscle control in a movement, such as throwing a ball or pushing a cursor. Primatologists do not doubt that differences in muscle control are sometimes important to apes engaged in the sort of activities discussed here; however, we have no way of studying this in wild animals. Rather, the focus of all work discussed here will usually be higher level analysis, the organization of individual elements of action (such as throwing or pushing) into complexes that serve to accomplish tasks. Manual skill, therefore, is here taken to be the sum of psychological processes that enable the development and perfection of complex, goal-directed manual skills by individuals.

\section{Cognition in the manual skills of living great apes}

Evidence on living apes comes from very different sources, for good reason when it reflects ecological specialization in different species, and also because of coincidences of what aspects have attracted the most research. This means comparison is not straightforward. I first examine the different genera, before attempting an overall summary of cognitive capacities common to the clade.

\section{Pan: the chimpanzee species}

The two species of chimpanzee, Pan troglodytes and Pan paniscus, were recognized as distinct from each other in the 1920s, but scientific study has always focused on the more common species, Pan troglodytes. The discovery that common chimpanzees not only use but make tools (Goodall, 1964) has accentuated this research emphasis. Little field data was available on Pan paniscus, the bonobo or pygmy chimpanzee, until the 1970s (Badrian \& Badrian, 1984; Badrian \& Malenky, 1984; Kano, 1982, 1983). Long-term study at two sites has subsequently failed to find any tool use involving skilled manipulation or tool manufacture in bonobos (but see Ingmanson, 1989, 1996), and their foraging and food processing skills have yet to be studied. One captive bonobo, however, readily learned to make stone flakes to cut rope securing a food box (Toth, et al., 1993). He largely worked by throwing his stone core at a hard substrate, with no need of careful aim, so there may be no real difference in mental capacities between $P$. paniscus and P. troglodytes (see McGrew, 1989). The manual skills of Pan, then, are better gauged from behaviour recorded in P. troglodytes 
Most chimpanzee tool use shows no particular sign of mental capacities beyond the association of tool and task, and it is hard to establish how deeply tool users understand the cause-and-effect relations of what they are doing - the main cognitive ability that is relevant (but see Limongelli, Boysen, \& Visalberghi, 1995). However, there is evidence that chimpanzee tool use is pre-planned, not evoked by stimuli in the situation of use. Stone hammers are sometimes selected in advance of use, according to criteria of fitness for purpose, then transported up to 0.5 $\mathrm{km}$ to the nut-cracking site (Boesch \& Boesch, 1983, 1984); insect fishing probes are sometimes made in advance to a simple pattern, then carried to the termite mound (Goodall, 1986, 1973). Tool selection or manufacture prior to transport to the site of use clearly indicates mental specification of the goal in advance of need (anticipatory schema). Their tool making has not shown corrective guidance, on-line, with detailed comparison with the goal specification: no error-correction during manufacture has been described. However, this may be a function of the difficulty of detection. Error correction in tool use has been seen, a stone wedge used to straighten an anvil stone for more efficient use (Matsuzawa, 1996). This may have been a response to practical failure, so we cannot be sure that the modification reflected recognizing a mismatch with a pre-conceived plan. Chimpanzees at Mt Niéniokoué, Ivory Coast, apparently evaluate nuts they intend to crack, giving a single blow and then sometimes abandoning the task: they appear to observers to be testing nuts' weight, maturity and density, all factors affecting the task of cracking (F Joulian, pers. comm.). These impressions, if confirmed, may reflect on-line corrective guidance of the nut-cracking task.

Despite the awkwardness of the chimpanzee hand, with relatively long fingers and short thumb (Napier, 1960), chimpanzees show precision handling and bimanual role differentiation in numerous ways when they make and use tools. They make probe tools used to "dip" for ants are by holding a stick in one hand and stripping protruding leaves or bark with the other, using a precision grip; they steady wobbly anvils with one hand while the other wields the hammerstone; etc. (Boesch \& Boesch, 1983, 1990) In addition, bimanual role differentiation and precise, visually-guided handling are shown in manual body grooming (Goodall, 1986), and in manual preparation of woolly-surfaced leaves of the sugar mulberry Broussonettia, difficult to eat without rolling (Stokes \& Byrne, 2001).

One task that nicely shows the advantage of precision handling and bimanual control is that of eating aggressive Dorylus ants. To capture these ants, chimpanzees insert a stick into a mass of ants and agitate it, provoking the ants to attack and climb the stick. At Taï, chimpanzees wait until about $10 \mathrm{~cm}$ of a relatively short stick is covered with ants and then pick off the ants with the lips (Boesch \& Boesch, 1990). At Gombe, chimpanzees wait until around $30 \mathrm{~cm}$ of a 
long wand is covered with ants. Then, with a sweeping movement of the other hand, half-closed in a precision grip, they accumulate a mass of ants which they eat rapidly (McGrew, 1974). This difference in technique probably reflects local adaptation to the various species of Dorylus ants, which vary in aggressiveness, since at Bossou, Guinea, where several species occur, individual chimpanzees use both techniques differentially, according to the species of ant and its current activity (T. Humle, pers comm).

The manual technique for eating Broussonettia leaves gives some evidence of hierarchical organization (Stokes \& Byrne, 2001). Hierarchical structure has not been explicitly shown for any chimpanzee tool using task, although this is most likely only because cognitive organization has seldom been examined. Matsuzawa (2001), suggests that a wide range of chimpanzee toolusing shows hierarchical organization, in a somewhat different way.

Certainly, sequential task organization towards an eventual goal, sometimes in several stages, is shown in many chimpanzee tool-using tasks. Examples are insect fishing and hammer-and-anvil use, in each of which the sequence may start with preparing or selecting a tool and transporting it to the site of use. Iteration of a regular string of actions until a criterion is reached gives evidence that the iterated string constitutes a subroutine of the main process (Byrne, 1999a): repeatedly agitating a dipping stick until ants reach a predetermined point, or repeatedly moving a stone anvil about until it is level, suggest this form of organization.

Moreover, the manufacture and use of several different tools in series to obtain a single goal has occasionally been noted (Brewer \& McGrew, 1990; Suzuki, Kuroda, \& Nishihara, 1995), again suggesting the ability to apply a regular and systematic sequence of actions, although each tool might have been made in response only to the outcomes of the previous tool's use.

Manual laterality in chimpanzees has been studied for many years, with controversy in both methods and conclusions (see Finch, 1941; Hopkins \& Morris, 1993; Marchant \& McGrew, 1991; McGrew \& Marchant, 1991). Now a clearer picture is beginning to emerge. In most spontaneous manual actions in the wild, individuals are generally ambidextrous (Marchant \& McGrew, 1996). However, individual lateralization has been found to be high in termite fishing (McGrew \& Marchant, 1992), stone tool use (Boesch, 1991; Sugiyama, Fushimi, Sakura, \& Matsuzawa, 1993), and manually cracking large Strychnos fruits (fruits must be pounded, accurately, against a hard object to break them: McGrew, Marchant, Wrangham, \& Klein, 1999). This collection of tasks suggests that lateralization is a strategy for enhancing manual precision, particularly if accurately aimed blows are necessary: presumably, one hand can specialize in perfecting a particularly difficult skill. In termite fishing, exclusively lateralized chimpanzees worked more quickly than weakly lateralized or ambidextrous individuals (McGrew \& Marchant, 
1999), although they must suffer corresponding disadvantages, compared with ambidextrous individuals, from having to adjust their posture to each termite mound. However, manual laterality is found in a plethora of other contexts and animal species (see review by Bradshaw \& Rogers, 1993), suggesting there may be reasons for lateralized function beyond simple efficiency. Bimanual role differentiation, which also serves task complexity, may be one of these other reasons: in captive chimpanzees, strong laterality was evoked by a task requiring bimanual solution, prising out food from a hollow object held in the other hand (Hopkins, 1995).

Assessment of whether population right-handedness occurs depends on which statistical methods are considered adequate (Hopkins, 1999; McGrew \& Marchant, 1991), but on current evidence there is no sign of this distinctively human trait in wild chimpanzees (McGrew \& Marchant, 1996).

\section{Gorilla: the gorilla species.}

Gorillas exist in two widely separated populations, whose obvious morphological differences are at last leading towards their recognition as species (Groves, 2000), the western Gorilla gorilla and the eastern Gorilla beringei. All captive studies concern the former, whereas all field studies on manual behaviour concern one subspecies of the latter, the mountain gorilla $G . b$. beringei. The gorilla hand is more human proportioned than the chimpanzee hand (Christel, 1993; Napier, 1960, 1961), and in captivity, western gorillas readily make tools (McGrew, 1989; Parker, Kerr, Markowitz, \& Gould, 1999), but no tool use of any sort has been reported from the wild. Instead, mountain gorillas use complex and skilful techniques for gathering and processing plant material (Byrne \& Byrne, 1991; Byrne \& Byrne, 1993; Byrne, Corp, \& Byrne, 2001a; Schaller, 1963), and it is in these tasks that the clearest evidence of cognitively driven manual skill is shown.

Mountain gorillas need considerable manual skill to obtain adequate nutrition, because their four major foods are all plants that are "defended" physically in ways that impede consumption (Byrne, 1999b). Thus, Laportea nettles are covered with stinging hairs; Carduns thistles, with spines; Pencedanum celery, with hard outer casing; and Galium bedstraw, with tiny hooks. Gorillas' techniques for dealing with these problems are complex, with several different actions organized into a regular sequence that is effective in removing or rendering harmless the various defences while efficient in rapidly amassing plant matter ready for eating (Byrne, Corp, \& Byrne, 2001b).

Individual actions show considerable precision handling and bimanual role differentiation (Byrne, et al., 2001a): for instance the deft folding and re-grasping of a whorl of 
sting-covered nettle leaves, which wraps the worst stings safely inside a single leaf. The organization of the tasks is not simply a chain, but a flexible hierarchy of control (Byrne \& Byrne, 1993; Byrne \& Russon, 1998). Hierarchical control means that processing stages which are occasionally unnecessary may be omitted (e.g., cleaning off debris before eating), local difficulties during the execution of a sequence can be handled by several alternative processes (e.g., substituting unimanual for normal bimanual accumulation of leaves, when one hand is needed for support in a tree), and series of processes may be treated as a single subroutine (such as iteration of the processes of procuring a nettle, stripping the stem of leaves, and removing petioles from those leaves, to the criterion of an adequately sized handful).

Finally, mountain gorilla manual lateralization is very strong in plant preparation. Techniques for consuming these four main foods are all bimanual, with left- and right-handed forms differing in which particular actions are done by each hand. For all four foods, almost every individual in the study population of 38 showed very strong preference for either right- or left-handed methods: almost none were ambidextrous (Byrne and Byrne, 1991). Moreover, for processing both celery pith and thistle leaves, individuals with the strongest lateralization were the quickest to prepare handfuls for eating: as in chimpanzees, lateralization makes for more efficient performance (Byrne \& Byrne, 1991). Intriguingly, a mountain gorilla seems to have two "hand preferences", for leaf and stem processing respectively. For the three very different techniques by which leaves are processed, gorillas that were (say) right-handed on one task were also right-handed on the other two, just as in most skilled manual tasks in humans. However, knowing an individual's laterality of leaf-processing does not in the slightest predict its (equally strong) hand preference for stem-processing. At the population level, no handedness was found for stem-processing but hand preferences for each of the three leaf-processing tasks were significantly skewed. More individuals preferred performing the most delicate actions righthanded, with the left hand giving grip support (Byrne \& Byrne, 1991). The strongest bias was found for Carduus thistle, 64\% right-handed and individuals with an exclusive hand-preference (i.e. 100\% for left or right) were significantly right biased (McGrew \& Marchant, 1996). This pattern seems to be the closest to human handedness yet found in any animal: several different tasks each evoke strong behavioural laterality, such that individuals have the same preference for each, and over the population there is a significant bias towards right-handed fine manipulation in all of them.

Comparing the gorilla data with the cognitive skills evidenced in human tool-making, conspicuous absences are the lack of aimed blows (which may simply reflect lack of need) and of corrective guidance based on anticipatory schema (which, as already noted, is difficult to detect). 
What is striking is that gorilla plant-feeding without tools provides remarkably similar evidence of complex cognition as that provided by chimpanzee tool use and manufacture. Indeed, but for west African chimpanzees' stone hammer and anvil use, gorillas would furnish better evidence of cognitive sophistication in manual skill, because hierarchical organization is more firmly established and hand-preferences at individual and population level are stronger. This Pan/Gorilla comparison supports a picture of the two genera as cognitively rather similar (Byrne, 1996), rather than of the gorilla as having lost many cognitive capacities still present in the chimpanzee (Povinelli, 1993).

\section{Pongo: the orangutan subspecies}

Although Bornean Pongo p. pygmaeus and Sumatran Pongo p. abelii orangutans differ as much genetically as the two chimpanzee species (Begun, 1999), they are usually treated as the same species. Comparing the two is complicated by the fact that their forest ecology differs markedly, at least at well-studied sites. Bornean forests are impoverished in fruit production compared to Sumatran. In Sumatra, tigers still range and large fruiting trees occur that act as magnets to orangutans. Therefore, Sumatrans more often congregate in groups and Borneans may rely more heavily on difficult fall-back foods like bark (van Schaik et al, 1999).

Wild orangutan tool use is rare. Individuals probe into arboreal bees' nests with a stick to obtain grubs and honey; they use a stick to scrape out irritating hairs within Neesia fruit, then prise the edible seeds from the husk so they can be safely eaten (Fox et al., 1999). These tool habits reveal a basic difference from African apes. Whereas chimpanzees or gorillas would use their hands for the fine motor control needed in comparable tasks, orangutans often transfer the stick to the mouth (Fox, et al., 1999; see also O’Malley \& McGrew, 2000, Russon 2002). Orangutan tool using may involve precision "mouthing" more than precision "handling". The much greater mobility of chimpanzee lips from those of gorillas has often been remarked, but the difference with orangutans is apparently even more marked.

Like gorillas, orangutans also confront many challenging plant foods, which often present multiple rather than single defences (Fox et al., 1999; Russon, 1998, 1999a, in press), and in addition their efforts to copy various complex human activities have been studied closely (Russon, 1997, 1999b; Russon \& Galdikas, 1993, 1995). These behaviours provide a rich source of data on manual skill. Delicate care in visually-guided precision handling is evident: for instance, when a rehabilitant poured kerosene onto smouldering embers of a fire, poured coffee from one narrow necked bottle into another, or threaded a rope through a metal ring. Hierarchical organization of plans has also been described: for instance, attaining the (prohibited) 
goal of "washing" laundry with stolen soap entailed a whole series of actions — untying a canoe, rocking it side to side to remove the bilge water, punting it to the otherwise inaccessible raft where laundry and soap could be had, etc. (Byrne \& Russon, 1998). In eating meristematic tissue from the base of new Borassodendron borneensis palm leaves, free-ranging rehabilitants show a systematic and hierarchically organized approach (Russon, 1998). The long action sequence in this process is evident, from constructing a clear working zone in the palm's crown, to complex subdivision and extraction of the leaf, to final departure while still eating carefully cached leftovers . Orangutans often begin by lightly fingering the leaf, as if checking it; then they either abandon it (as if it were undesirable) or proceed to prepare a work zone to facilitate extraction; they may also pause mid-sequence to correct errors or handle interruptions (Russon, pers. comm.). These adjustments suggest the use of on-line corrective guidance; leaf-testing, like Mt. Niéniokoué chimpanzees' nut testing, suggests correction based on anticipatory schema. Like gorillas, orangutans may have little natural need for percussive tool use, but rehabilitants spontaneously bang termite nest chunks together to crack them open and once hammered a hole through the concrete floor of their cage with scavenged chunks of cement (Russon, 2000, pers. comm.), and one captive readily learned to flake stone to produce sharp flakes (but with human tuition and assistance: Wright, 1972). Most of these examples concern individuals with some degree of human experience, so better confirmation from wild orangutans is desirable, but present evidence indicates that orangutans show most of the cognitive attributes evident in African great apes.

Evidence on manual lateralization in orangutans is relatively sparse, but Rogers and Kaplan (1996) found no population trend in hand preferences when food processing, and even individual lateral preferences varied widely. Considerable use of bimanual role differentiation in feeding was found in some individuals (e.g. CID, in Fig 5 on p.21), suggesting that such motor control is quite possible in orangutans.

\section{Conclusions}

Table 1 offers an attempt to summarize current evidence on the cognitively driven manual skills of the living great apes. Living great apes, to summarize briefly, can use their considerable abilities of precise handling of objects and bimanual role differentiation to construct motor skills that involve a regular, sequential plan of many actions, some of which are hierarchically organized-with resulting flexibility of tool and manual problem-solving in the physical domain. Characteristically, these complex skills involve lateralized processing in individuals. 


\section{TABLE 1 ABOUT HERE}

Inevitably, these judgements have an element of subjectivity, but in general the lack of difference across species is clear, especially among the African apes, as are the cognitive similarities underlying manual and tool skills. (see Yamakoshi, this volume, for consistent findings using a different approach.) Partly, this conclusion may reflect the lack of descriptive work sensitive enough to characterize fine details of motor control and planning, and real differences may yet appear. But on the aspects analysed here, it seems more likely that as evidence accumulates (especially from the less-studied Pongo and Gorilla) apparent differences are more likely to disappear, except in so far as they reflect responses to ecological need.

In many ways, this suite of capacities in living apes closely resembles that inferred for extinct, bipedal apes on the human line (Paranthropus, Australopithecus, Homo babilis, etc.). Other aspects of the behaviour of living apes also suggest similarities in cognition to those extinct species. In the elegantly flaked tools from Lokalalei, conclusive evidence of on-line guidance from comparison with a mental anticipation (schema) is apparently lacking (Roche et al, 1999). Only with the visible traces of corrections during the manufacture of much later hand axes, of Homo erectus and subsequent species, does this become incontrovertible. Alternatively, many archaeologists would argue that guidance by mental schema is strongly suggested in more ancient stone tool repertoires; but equally, many primatologists would argue the same from the skilled behaviour of living apes. Nothing like the $90 \%$ right handedness typical of modern human populations is known in any living ape population. However, claims of right-handed manufacture of early stone tools are also controversial (Toth, 1985a). Further, until the reasons for laterality in living apes are better understood, no useful comparison can be made. Strong individual laterality is associated with increased efficiency (Gorilla: Byrne and Byrne, 1991; Pan: McGrew and Marchant, 1999), but population right-handedness is at best relatively weak, and shown convincingly in the wild only in gorilla leaf-processing tasks (Byrne \& Byrne, 1991; McGrew \& Marchant, 1996).

The question then becomes, where do the real differences in cognitive capacities lie, and are these differences likely to be critical ones for human evolution? In Table 1, chimpanzees (and, less conclusively, orangutans) are noted as able to aim relatively accurate and powerful blows, most clearly shown by chimpanzees using stone hammers and anvils. Hammer and anvil use is much slower to acquire than any other manual skill in any ape species (Boesch \& Boesch, 1983), and experimental induction of stone flaking in one orangutan and one bonobo did not result in 
either individual learning to strike flakes off a hand-held core. Evidently, accurately aimed hitting does not come easily to living apes. Moreover, apes' level of accuracy is unlikely to be anywhere near that shown in the stone tools of Lokalalei, where there is evidence of very precise control of force and blows to detach flakes in a regular, planned sequence. The ability to control blows this precisely aimed but still powerful seems to be a crucial adaptation of the human lineage. Incorporating these refined actions into an organized, planned sequential program is something that apes already do. (It seems a suspicious coincidence that the cognitive capacity that emerges as crucial happens to be almost the only one that current archaeological methods are capable of showing before 2Ma. Perhaps the Lokalalei tool-makers had other skills we can only guess at.)

These conclusions suggest that human manual skill has a relatively long evolutionary history, that can usefully be studied in living apes as well as archaeologically. The extinct bipedal apes of 4 Mya to 2 Mya that made stone tools were very different animals to any other living species, but the cognitive capacities of chimpanzees, gorillas and orangutans are appropriately compared to those of these first stone tool-makers.

In beginning to make such comparisons, and developing an integrated understanding of the cognition that lies behind manual skills in both human and non-human apes, it is important that all evidence of advanced manual skill be utilized. My frequent and (I hope) telling uses of data from plant processing show that evidence should not be sought only from skills involving tools. Tool use per se has a mystique that risks distorting our perspective away from recognizing other manifestations of complex manual ability. Focusing attention on the cognitive capacities that skilled behaviour can indicate, whether or not tools are involved, should allow a better understanding of great ape as well as human intellectual origins. 


\section{Footnote}

1. A single name for this group of species would be convenient, and traditionally the term was "hominids": defined as extinct relatives of modern humans that were bipedal, more closely related to ourselves than to any living animal, but not quite human. Usage varied slightly in whether Homo species other than sapiens were described as "hominids" or simply humans, but genera like Australopithecus, Paranthropus and Ardipithecus were always referred to as (early) hominids. Unfortunately, "hominid" now has at least two meanings. Modern taxonomy recognizes the remarkably close relationship between humans and the living great apes (Begun, 1999), and now includes some or all of them among the hominids. Sometimes only the African great apes, including Homo, are included, with the Asian orangutans remaining in the family Pongidae; sometimes all the great apes, including Homo and also Pongo, are treated as hominids. Meanwhile, many palaeontologists keep to the original usage. For clarity, the term is avoided in this chapter. 
Table 1

\begin{tabular}{|llll|}
\hline & Pan & Gorilla & Pongo \\
\hline precision handling & $\checkmark$ & $\checkmark$ & $\checkmark$ \\
\hline accurately aimed, powerful blows & $\checkmark$ & $?$ & $(\checkmark)$ \\
\hline bimanual role differentiation & $\checkmark$ & $\checkmark$ & $(\checkmark)$ \\
\hline regular, sequential plan & $\checkmark$ & $\checkmark$ & $(\checkmark)$ \\
\hline hierarchical organization & $(\checkmark)$ & $\checkmark$ & $(\checkmark)$ \\
\hline corrective guidance by schema & $(\mathbf{X})$ & $(\mathbf{X})$ & $?$ \\
\hline strong individual lateralities & $\checkmark$ & $\checkmark$ & $(\checkmark)$ \\
\hline population right-handedness & $(\mathbf{X})$ & $\checkmark$ & $\mathbf{X}$ \\
\hline
\end{tabular}

The symbol $\checkmark$ indicates substantial positive evidence; $\mathbf{X}$ the lack of such evidence despite extensive study; brackets indicate that evidence is inconclusive, usually because it came from only one or two individuals; and ? implies that the topic has apparently not been studied. Sources on which these subjective judgements were based are included in the text. 


\section{References}

Badrian, A., \& Badrian, N. (1984). Social organisation of Pan paniscus in the Lomako forest, Zaire. In The pigmy chimpanzee: Evolutionary biology and behaviour, ed. R. L. Susman, pp. New York: Plenum Press.

Badrian, N. L., \& Malenky, R. K. (1984). Feeding ecology of Pan paniscus in the Lomako Forest, Zaire. In The pygmy chimpanzee: evolutionary biology and behaviour, ed. R. L. Susman, pp. 275-299. New York: Plenum.

Beck, B. B. (1980). Animal tool behaviour. New York: Garland Press.

Begun, D. R. (1999). Hominid family values: morphological and molecular data on relations among the great apes and humans. In The mentalities of gorillas and orangutans. Comparative perspectives, ed. S. T. Parker, R. W. Mitchell, \& H. 1. Miles, pp. 3-42. Cambridge: Cambridge University Press.

Boesch, C. (1991). Handedness in wild chimpanzees. International Journal of Primatology, 12, 541-558.

Boesch, C., \& Boesch, H. (1983). Optimisation of nut-cracking with natural hammers by wild chimpanzees. Behaviour, 83, 265-286.

Boesch, C., \& Boesch, H. (1984). Mental map in wild chimpanzees: an analysis of hammer transports for nut cracking. Primates, 25, 160-170.

Boesch, C., \& Boesch, H. (1990). Tool use and tool making in wild chimpanzees. Folia Primatologica, 54, 86-99.

Bradshaw, J., \& Rogers, L. (1993). The evolution of lateral asymmetries, language, tool use, and intellect. San Diego: Academic Press.

Brewer, S., \& McGrew, W. C. (1990). Chimpanzee use of a tool-set to get honey. Folia Primatologica, 54, 100-104.

Bril, B., Roux, V., \& Dietrich, G. (2000). Skills involved in the knapping of chalcedony beads: motor and cognitive characteristics of a complex situated action. In Cornaline de l'Inde: des pratiques de Cambay aux techno-systèmes de l'Indus, ed. V. Roux, pp. Paris: Editions de la Maison des sciences de l'homme.

Bruner, J. (1970). The growth and structure of skill. In Mechanisms of motor skill development, ed. K. J. Connolly, pp. 63-94. New York: Academic Press.

Byrne, R. W. (1996). The misunderstood ape: cognitive skills of the gorilla. In Reaching into thought; the minds of the great apes, ed. A. E. Russon, K. A. Bard, \& S. T. Parker, pp. 111-130. Cambridge: Cambridge University Press.

Byrne, R. W. (1999a). Imitation without intentionality. Using string parsing to copy the organization of behaviour. Animal Cognition, 2, 63-72. 
Byrne, R. W. (1999b). Cognition in great ape ecology. Skill-learning ability opens up foraging opportunities. Symposia of the Zoological Society of London, 72, 333-350.

Byrne, R. W., \& Byrne, J. M. E. (1991). Hand preferences in the skilled gathering tasks of mountain gorillas (Gorilla g. beringei). Cortex, 27, 521-546.

Byrne, R. W., \& Byrne, J. M. E. (1993). Complex leaf-gathering skills of mountain gorillas (Gorilla g. beringę): Variability and standardization. American Journal of Primatology, 31, 241-261.

Byrne, R. W., Corp, N., \& Byrne, J. M. (2001a). Manual dexterity in the gorilla: bimanual and digit role differentiation in a natural task. Animal Cognition, 4, 347-361.

Byrne, R. W., Corp, N., \& Byrne, J. M. E. (2001b). Estimating the complexity of animal behaviour: How mountain gorillas eat thistles. Behaviour, 138, 525-557.

Byrne, R. W., \& Russon, A. E. (1998). Learning by imitation: a hierarchical approach. Behavioral and Brain Sciences, 21, 667-721.

Chevalier-Skolnikoff, S., \& Liska, J. (1993). Tool use by wild and captive elephants. Animal Behaviour, 46(2), 209-219.

Christel, M. (1993). Grasping techniques and hand preferences in Hominoidea. In Hands of Primates, ed. H. Preuschoft \& D. J. Chivers, pp. 91-108. New York: Springer Verlag.

Connolly, K. J. (1998). The psychobiology of the hand. Cambridge: Mac Keith Press.

de Groot, A. D. (1965). Thought and choice in chess. The Hague: Mouton.

Elliott, J., \& Connolly, K. (1974). Hierarchical structure in skill development. In The growth of competence, ed. K. Connolly \& K. Bruner, pp. 135-168. London: Academic Press.

Elliott, J. M., \& Connolly, K. J. (1984). A classification of manipulative hand movements. Developmental Medicine \& Child Neurology, 26, 283-296.

Finch, G. (1941). Chimpanzee handedness. Science, 94, 117-118.

Fitts, P. M., \& Posner, M. I. (1967). Human performance. Belmont, CA: Brooks/Cole Publishing Company.

Fox, E., Sitompul, A., \& Van Schaik, C. P. (1999). Intelligent tool use in wild Sumatran orangutans. In The mentality of gorillas and orangutans, ed. S. T. Parker, H. L. Miles, \& R. W. Mitchell, pp. 99-116. Cambridge: Cambridge University Press.

Galdikas, B. M. F. (1982). Orang-utan tool use at Tanjung Puting Reserve, Central Indonesian Borneo (Kalimantan Tengah). Journal of Human Evolution, 10, 19-33.

Goodall, J. (1964). Tool-using and aimed throwing in a community of free-living chimpanzees. Nature, 201, 1264-1266.

Goodall, J. (1986). The chimpanzees of Gombe: patterns of behavior. Cambridge, MA: Harvard University Press. 
Goodall, J. v. L. (1973). Cultural elements in a chimpanzee community. In Precultural Primate Behaviour, ed. E. W. Menzel, pp. 144-184. Basel: Karger.

Goodall, J.v.L and van Lawick, H. (1966). On the use of tools by the Egyptian vulture, Neophron percnopterus. Nature, 212, 1468-9.

Gosselain, O.P. (2000). Materializing identities: An African perspective. Journal of Archaeological Method and Theory, 7(3), 187-217.

Groves, C. (2000). What, if anything, is taxonomy? Gorilla Journal, 21, 12-15.

Hopkins, W. D. (1995). Hand preferences for a coordinated bimanual task in 110 chimpanzees (Pan troglodytes): cross-sectional analysis. Journal of Comparative Psychology, 109, 291-297.

Hopkins, W. D. (1999). On the other hand: Statistical issues in the assessment and interpretation of hand preference data in nonhuman primates. International Journal of Primatology, 20, 851-866.

Hopkins, W. D., \& Morris, R. D. (1993). Handedness in great apes: a review of findings. International Journal of Primatology, 14, 1-25.

Hunt, G. R. (1996). Manufacture and use of hook-tools by New Caledonian crows. Nature, 379 , 249-251.

Hunt, G. R. (2000). Tool use by the New Caledonian crow Corvus moneduloides to obtain Cerambycidae from dead wood. Emu, 100, 109-114.

Ingmanson, E. J. (1989). Branch dragging by pygmy chimpanzees at Wamba, Zaire - the use of objects to facilitate social communication in the wild. American Journal of Physical Anthropology, 78, 244.

Inizian, M.-L., Reduron-Ballinger, M., Roche, H., \& Tixier, J. (1999). Technology and technology of knapped stone. Nanterre: CREP.

Joulian, F. (1996). Comparing chimpanzee and early hominid techniques: some contributions to cultural and cognitive questions. In Modelling the early buman mind, ed. P. Mellars \& K. Gibson, pp. 173-189. Cambridge: McDonald Institute for Archaeological Research.

Kano, T. (1982). The social group of pygmy chimpanzees of Wamba. Primates, 23, 171-188.

Kano, T. (1983). An ecological study of the pygmy chimpanzees (Pan paniscus) of Yalosidi, Republic of Zaire. International Journal of Primatology, 4, 1-31.

Kortlandt, A. (1967). Experimentation with chimpanzees in the wild. In Neue Ergebnisse der Primatologie, ed. D. Starck, R. Schneider, \& H. J. Kuhn, pp. Stuttgart: Gustau Fisher Verlag.

Lashley, K. S. (1951). The problem of serial order in behaviour. In Cerebral mechanisms in behaviour: the Hixon Symposium, ed. L. A. Jeffress, pp. 112-136. New York: Wiley.

Limongelli, L., Boysen, S. T., \& Visalberghi, E. (1995). Comprehension of cause-effect relations in a tool-using task by chimpanzees (Pan troglodytes). Journal of Comparative Psychology, 109, 18-26. 
Marchant, L. F., \& McGrew, W. C. (1991). Laterality of function in apes: a meta-analysis of function. Journal of Human Evolution, 21, 425-438.

Marchant, L. F., \& McGrew, W. C. (1996). Laterality of limb function in wild chimpanzees of Gombe National Park: comprehensive study of spontaneous activities. Journal of Human Evolution, $30,427-443$.

Marchant, L. F., McGrew, W. C., \& Eibl-Eibesfeldt, I. (1995). Is human handedness universal? Ethological analyses from three traditional cultures. Ethology, 101, 239-258.

Marzke, M. W., \& Wullstein, K. L. (1995). Chimpanzee and human grips: A new classification with a focus on evolutionary morphology. International Journal of Primatology, 17(1), 117-139.

Matsuzawa, T. (1996). Chimpanzee intelligence in nature and captivity: isomorphism of symbol use and tool use. In Great ape societies, ed. W. C. McGrew, L. F. Marchant, \& T. Nishida, pp. 196-209. Cambridge: Cambridge University Press.

Matsuzawa, T. (2001). Primate foundations of human intelligence: a view of tool use in nonhuman primates and fossil hominids. In Primate origins of human cognition and behavior, ed. T. Matsuzawa, pp. 3-25. Tokyo: Springer-Verlag.

McGrew, W. C. (1974). Tool use by wild chimpanzees feeding on driver ants. Journal of Human Evolution, 3, 501-508.

McGrew, W. C. (1989). Why is ape tool use so confusing? In Comparative socioecology: the behavioural ecology of humans and other mammals, ed. V. Standen \& R. A. Foley, pp. 457-472. Oxford: Blackwell Scientific Publications.

McGrew, W. C. (1992). Chimpanzee material culture: implications for human evolution. Cambridge: Cambridge University Press.

McGrew, W. C., \& Marchant, L. F. (1991). Laterality of function in apes: A critical review. American Journal of Physical Anthropology, 84(Supplement 12), 129-130.

McGrew, W. C., \& Marchant, L. F. (1992). Chimpanzees, tools, and termites: Hand preference or handedness? Current Anthropology, 33, 114-119.

McGrew, W. C., \& Marchant, L. F. (1996). On which side of the apes? Ethological study of laterality of hand use. In Great ape societies, ed. W. C. McGrew, L. F. Marchant, \& T. Nishida, pp. 255-272. Cambridge: Cambridge University Press.

McGrew, W. C., \& Marchant, L. F. (1999). Laterality of hand use pays off in foraging success for wild chimpanzees. Primates, 40(3), 509-513.

McGrew, W. C., Marchant, L. F., Wrangham, R. W., \& Klein, H. (1999). Manual lateraility in anvil use: wild chimpanzees cracking Strychnos fruits. Laterality, 4, 79-87. 
McManus, I. C. (1984). Genetics of handedness in relation to language disorder. Advances in Neurology, 42, 125-138.

Mellars, P. A., \& Stringer, C. (Ed.). (1989). The human revolution: behavioural and biological perspectives on the origins of modern humans. Princeton, NJ: Princeton University Press.

Miller, G. A., Galanter, E., \& Pribram, K. (1960). Plans and the structure of behavior. New York: Holt, Rinehart and Winston.

Napier, J. R. (1960). Studies of the hands of living primates. Proceedings of the Zoological Society of London, 134, 647-657.

Napier, J. R. (1961). Prehensility and opposability in the hands of primates. Symposia of the roological society of London, 5, 115-132.

Nishida, T. (1986). Local traditions and cultural transmission. In Primate Societies, ed. B. B. Smuts, D. L. Cheney, R. M. Seyfarth, R. W. Wrangham, \& T. T. Struhsaker, pp. 462-474. Chicago, Illinois and London: University of Chicago Press.

Oakley, K. P. (1949). Man the tool maker. London: Trustees of the British Museum.

Parker, S. T., Kerr, M., Markowitz, H., \& Gould, J. (1999). A survery of tool use in zoo gorillas. In The mentalities of gorillas and orangutans, ed. S. T. Parker, R. W. Mitchell, \& H. L. Miles, pp. 188-193. Cambridge: Cambridge University Press.

Pelegrin, J. (2000). The knapping methods and techniques practiced at Cambay. In Cornaline de l'Inde: des pratiques de Cambay aux techno-systemes de l'Indus, ed. V. Roux, pp. Paris: Editions de la Maison des sciences de l'homme.

Povinelli, D. J. (1993). Reconstructing the evolution of mind. American Psychologist, 48, 493-509.

Reynolds, P. C. (1982). The primate constructional system: The theory and description of instrumental tool use in humans and chimpanzees. In The analysis of action, ed. M. Van Cranach \& R. Haas, pp. 243-385. Cambridge: Cambridge University Press.

Riedman, M. L., Staedier, M. M., Estes, J. A., \& Hrabrich, B. (1989). The transmission of individually distinctive foraging strategies from mother to offspring in sea otters (Enhydra lutris). In Eighth Biennial Conference on the Biology of Marine Mammals. Pacific Grove CA:

Roche, H. (1989). Technological evolution in early hominids. Ossa, 14, 97-98.

Roche, H., Delegnes, A., Brugal, J.-P., Feibel, C., Kibunjia, M., Mourre, V., \& Texier, P.-J. (1999). Early hominid stone production and technical skill 2.34 Myr ago in West Turkana, Kenya. Nature, 399, 57-60.

Rogers, L. J., \& Kaplan, G. (1996). Hand preferences and other lateral biases in rehabilitated orangutans, Pongo pygmaeus pygmaeus. Animal Behaviour, 51(1), 13-25. 
Roux, V. (2000). Cornaline de l'Inde: des pratiques techniques de Cambay aux techno-systèmes de l'Indus. Paris: Editions de la Maison des sciences de l'homme.

Russon, A. (1998). The nature and evolution of intelligence in orangutans (Pongo pygmaeus). Primates, 39, 485-503.

Russon, A. E. (1997). Exploiting the expertise of others. In Machiavellian intelligence II: Extensions and evaluations, ed. A. Whiten \& R. W. Byrne, pp. 174-206. Cambridge: Cambridge University Press.

Russon, A. E. (1999a). Naturalistic approaches to orangutan intelligence and the question of enculturation. International Journal of Comparative Psychology, 12, 1-22.

Russon, A. E. (1999b). Orangutans' imitation of tool use: a cognitive interpretation. In The mentalities of gorillas and orangutans, ed. S. T. Parker, H. L. Miles, \& R. M. Mitchell, pp. 117-146. Cambridge: Cambridge University Press.

Russon, A. E. (2000). Orangutans. Wizards of the rainforest. Tokyo: Key Porter Publications.

Russon, A. E. (2002). Return of the native: Cognition and site-specific expertise in orangutan rehabilitation. International Journal of Primatology, 23, 467-478.

Russon, A. E. (in press). Comparative developmental perspectives on culture: The great apes. To appear in H. Keller, Y.H. Poortinga, \& Schoelmerich (eds.), Between Biology and Culture: Perspectives on Ontogenetic Development. Cambridge, UK: Cambridge University Press.

Russon, A. E., \& Galdikas, B. M. F. (1993). Imitation in free-ranging rehabilitant orangutans. Journal of Comparative Psychology, 107, 147-161.

Russon, A. E., \& Galdikas, B. M. F. (1995). Constraints on great ape imitation: model and action selectivity in rehabilitant orangutan (Pongo pymaeus) imitation. Journal of Comparative Psychology, 109, 5-17.

Schaller, G. B. (1963). The mountain gorilla. Chicago: Chicago University Press.

Stokes, E. J., \& Byrne, R. W. (2001). Cognitive capacities for behavioural flexibility in wild chimpanzees (Pan troglodytes):The effect of snare injury on complex manual food processing. Animal Cognition, 4, 11-28.

Sugiyama, Y. (1994). Tool use by wild chimpanzees. Nature, 367, 327.

Sugiyama, Y., Fushimi, T., Sakura, O., \& Matsuzawa, T. (1993). Hand preference and tool use in wild chimpanzees. Primates, 34, 151-159.

Sugiyama, Y., \& Koman, J. (1979). Tool-using and tool-making behaviour in wild chimpanzees at Bossou, Guinea. Primates, 20, 513-524.

Suzuki, S., Kuroda, S., \& Nishihara, T. (1995). Tool-set for termite-fishing by chimpanzees in the Ndoki Forest, Congo. Behaviour, 132, 219-235. 
Toth, N. (1985a). Archaeological evidence for preferential right-handedness in the lower and middle Pleistocene, and its possible implications. Journal of Human Evolution, 14, 607-614.

Toth, N. (1985b). The Oldowan reassessed: a close look at early stone artifacts. Journal of Archaeological Science, 12, 101-120.

Toth, N., Schick, K. D., Savage-Rumbaugh, E. S., Sevcik, R. A., \& Rumbaugh, D. M. (1993). Pan the tool-maker: investigations into the stone-tool-making and tool-using capabilities of a bonobo (Pan paniscus). Journal of Archaeological Science, 20, 81-91.

van Schaik, C. P. (1994). Tool-use in wild Sumatran orangutans (Pongo pygmaeus). Talk given at 15th Congress of IPS 3-8 August, Kuta, Bali:

van Schaik, C. P., Deaner, R. O., \& Merrill, M. Y. (1999). The conditions for tool-use in primates: implications for the evolution of material culture. Journal of Human Evolution, 36, 719-741.

Wright, R. V. S. (1972). Imitative learning of a flaked-tool technology - The case of an orang-utan. Mankind, 8, 296-306.

Wynn, T. (1988). Tools and the evolution of human intelligence. In Machiavellian Intelligence: Social Expertise and the Evolution of Intellect in Monkeys, Apes and Humans, ed. R. W. Byrne \& A. Whiten, pp. 271-284. Oxford: Clarendon Press.

Wynn, T., \& McGrew, W. C. (1989). An ape's view of the Oldowan. Man, 24, 383-398. 